\title{
Morphometry of the adult sigmoid colon and relation to volvulus
}

\author{
H. Saidi, BSc. (Anat), MBChB, MMed, D. Anangwe, BSc. (Anat), J. Ogeng'o, BSc. (Anat), MBChB and \\ K. Awori, MBChB, MMed, Department of Human Anatomy, College of Health Sciences, University of Nairobi, \\ P.O. Box 30197-00100, Nairobi, Kenya \\ Correspondence to: \\ Dr. H. Saidi, Department of Human Anatomy, College of Health Sciences, University of Nairobi, P.O. Box \\ 30197-00100, Nairobi, Kenya
}

\section{Abstract}

BACKGROUND:Thesigmoid colon in Africans is commonly affected by volvulus formation. Anatomical characteristics of this part of the colon could provide some of the contributory explanations for male gender predisposition.

METHOD: Ninety five sigmoid colons (fifty male subjects) were harvested at autopsy. The following measurements were made: length of the sigmoid colon, length of the mesocolon root, height of the mesocolon. The sigmoid length. mesocolic root length ratio and sigmoid length: mesocolic height ratios were also calculated. All means and ratios were compared for gender using the Student $\mathrm{t}$-test. $\mathrm{P}<0.05$ was considered statistically significant.

RESULTS: The mean sigmoid colon length was higher in males $(36.9 \mathrm{~cm})$ than in females $(32.6 \mathrm{~cm})(\mathrm{p}=0.007)$. Most $(41.7 \%)$ of the sigmoid colons measured $30-34.9 \mathrm{~cm}$ long. Males had shorter mesocolon roots and longer mesocolon heights.

CONCLUSION: The greater colon length and smaller mesocolic root lengths in males may be the anatomical basis for the higher incidence of sigmoid volvulus in males.

\section{Introduction}

The sigmoid colon is the commonest site for volvulus formation. The incidence of sigmoid volvulus shows both gender and population disparities being more common in males and in several developing countries (1-4). In Africa, epidemiological studies indicate a higher incidence of sigmoid volvulus in males than females with a male to female ratio ranging from 9:1 in South Africa $(5,6)$ to $13.5: 1$ in Ethiopia (7). Elsewhere, similar gender pattern is documented and is thought to be due to anatomical factors $(1,2)$. Sigmoid loops with tall mesocolons (dolichomesocolic) show a male predominance while loops with short mesocolons (brachymesocolic) depict a female predominance among Indians (1) and Caucasians (3). The literature on the morphometry of the sigmoid colon among Africans is limited (8).

This study describes the morphometric features of the sigmoid colon in adult Kenyans autopsied at a University and a city council mortuary in Nairobi.

\section{Materials and Methods}

Ninety five sigmoid colon specimens were obtained during autopsy examinations performed at the Chiromo and Nairobi city mortuaries. Ethical approval was obtained from the Kenyatta National Hospital Ethical Review Committee (KNH-ERC) before specimen retrieval from fifty adult males and forty five adult females. The ages of the subjects used 
ranged from twenty one to fifty six years. The effects of post mortem shrinkages were limited by taking measurements from subjects that had died within forty eight hours.

The colons were accessed through midline abdominal incisions used at autopsy. After reflection of the small intestines and the bladder (uterus in females), the sigmoid colons were identified and both the root and vertical lengths of sigmoid mesocolon were measured in situ (Figure 1). The length of the sigmoid colon at the antimesenteric border was also estimated (in centimeters) using a tape measure.

Two indices relating the total length of the sigmoid colon and the vertical height of the mesocolon to the length of the mesocolon root were calculated as shown;

- Index $1=$ sigmoid colon length/mesocolon root length (S 1/S3)

- Index $2=$ mesocolon vertical height mesocolon root length (S2/S3)

The results of the measurements were tabulated and analyzed using computer software and statistical package of social sciences (SPSS) for windows version 11.50, Chicago Illinois, 2002. The means and the calculated ratios were compared for males and females using the Student $t$-test. The level of significance was set at $\mathrm{P}<0.05$.

Figure 1: Morphometric parameters of the sigmoid loop and mesocolon. S1 - sigmoid colon length, S2mesocolon vertical height, S3- mesocolon root length

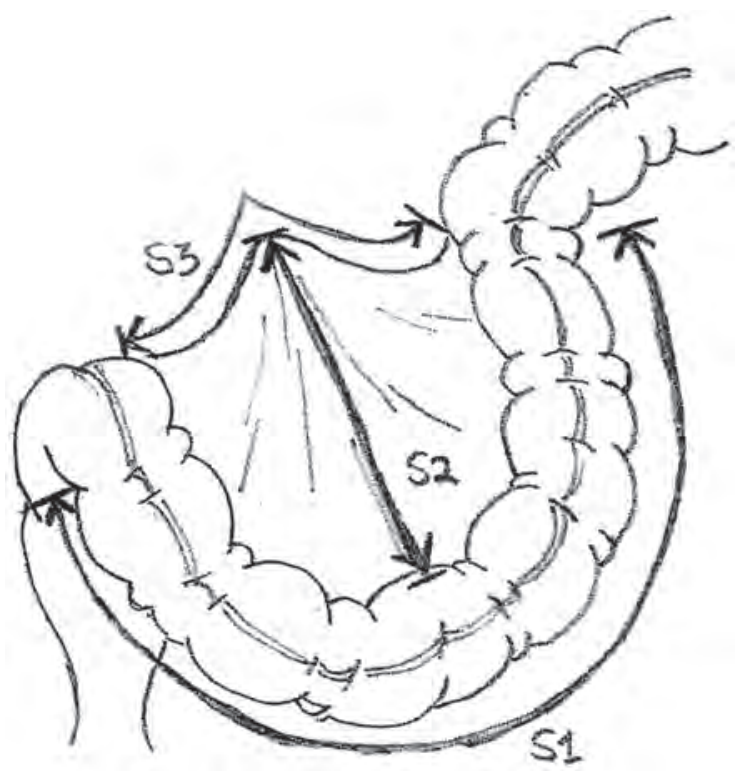

\section{Results}

The length of the sigmoid colon in the studied sample ranged from $27.6 \mathrm{~cm}$ to $46.7 \mathrm{~cm}$ in males and $27.1 \mathrm{~cm}$ to $40.2 \mathrm{~cm}$ in females. Most sigmoid colons measured $30-34.9 \mathrm{~cm}$ in length $(41.7 \%)$. The frequency of loops measuring $20-29.9 \mathrm{~cm}$, $35.39 .9 \mathrm{~cm}$ and $40-49.9 \mathrm{~cm}$ length was $15.3 \%$, $27.8 \%$ and $15.3 \%$ respectively.

The mean length for males $(36.9 \pm 5 \mathrm{~cm})$ was significantly longer than for females (32.6 $\pm 3.8 \mathrm{~cm})(p=0.007)($ Table 1$)$. The range of the mesocolic root length was $9.6 \mathrm{~cm}$ to $20.7 \mathrm{~cm}$ in males (mean $14.2 \pm 3.4 \mathrm{~cm}$ ) and $10.2 \mathrm{~cm}$ to $25.1 \mathrm{~cm}$ in females $(17.6 \pm 3.4 \mathrm{~cm})$.

The range of the mesocolic vertical height was $3.1 \mathrm{~cm}$ to $26.4 \mathrm{~cm}$ in males and $9.5 \mathrm{~cm}$ to $18.1 \mathrm{~cm}$ in females. The mean vertical height was $15.1 \pm 4.3 \mathrm{~cm}$ and $13.4 \pm 2.6 \mathrm{~cm}$ in males and females respectively (Table 1 , Figure 3 ).

The average value of index 1 (sigmoid colon length/mesocolon root length) was 2.68 in males and 1.76 in females $(p=0.004)$. The average value of index 2 (mesocolon vertical height/mesocolon root length) was 1.22 in males and 0.74 in females $(p=0.024)$.

Male subjects generally had longer sigmoid loop length, shorter mesocolic root lengths and longer mesocolic heights. Female subjects possessed shorter sigmoid loops, longer mesocolic root lengths and shorter mesocolic heights (Figures 2, 3 and 4).

Figure 2: Morphometry of sigmoid colon/mesocolon by gender

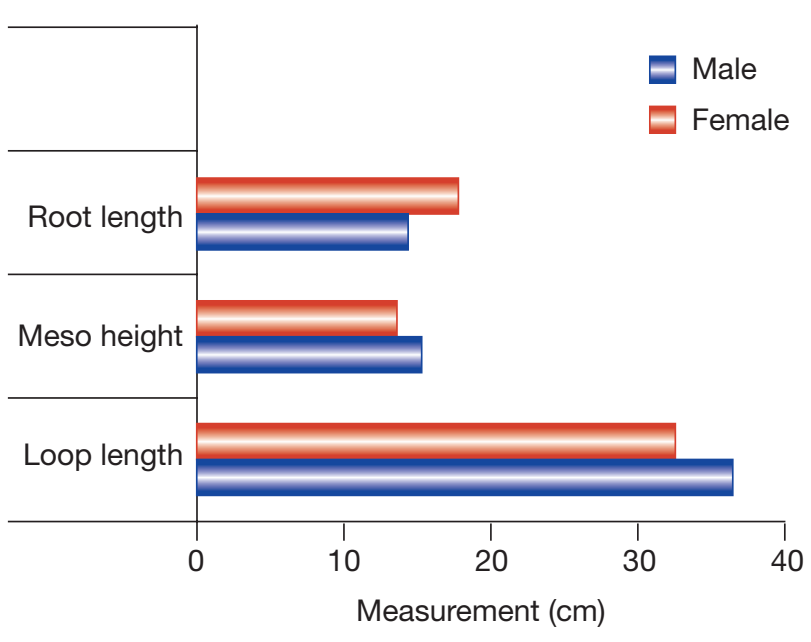


Table 1 Morphometry of the sigmoid colon and mesocolon in adult males and females

\begin{tabular}{|c|c|c|c|c|c|c|c|}
\hline \multirow[t]{2}{*}{ Gender } & \multicolumn{3}{|c|}{ Males } & \multicolumn{3}{|c|}{ Females } & \multirow[t]{2}{*}{ P-value } \\
\hline & Mean $(\mathrm{cm})$ & $\begin{array}{l}\text { Standard } \\
\text { deviation }\end{array}$ & Range (cm) & Mean $(\mathrm{cm})$ & $\begin{array}{l}\text { Standard } \\
\text { deviation }\end{array}$ & Range (cm) & \\
\hline Sigmoid colon length & 36.9 & 5.0 & $27.6-46.7$ & 32.6 & 3.8 & $27.1-40.2$ & 0.007 \\
\hline Mes vertical height & 15.1 & 4.3 & $3.1-26.4$ & 13.4 & 2.6 & $9.5-18.1$ & 0.067 \\
\hline Mes root length & 14.2 & 3.4 & $9.6-20.7$ & 17.6 & 3.4 & $10.2-25.1$ & 0.012 \\
\hline Index 1 & 2.68 & & & 1.76 & & & 0.004 \\
\hline Index 2 & 1.22 & & & 0.74 & & & 0.024 \\
\hline
\end{tabular}

Figure 3: Short mesocolon height of a thirty two year old female. The height was $3 \mathrm{~cm}$, the lowest recorded mesocolic parameter

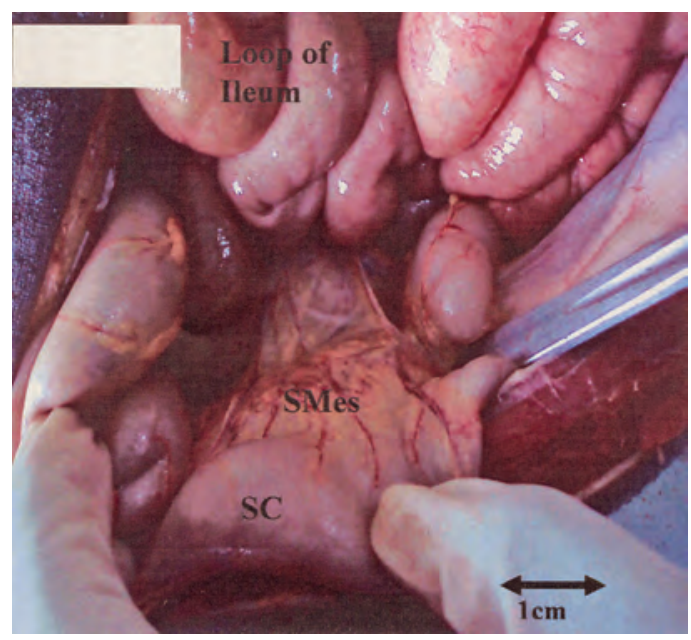

$\mathrm{SC}=$ Sigmoid colon; SMes = Sigmoid mesocolon

Figure 4b: The uncoiled sigmoid loop measured $46 \mathrm{~cm}$

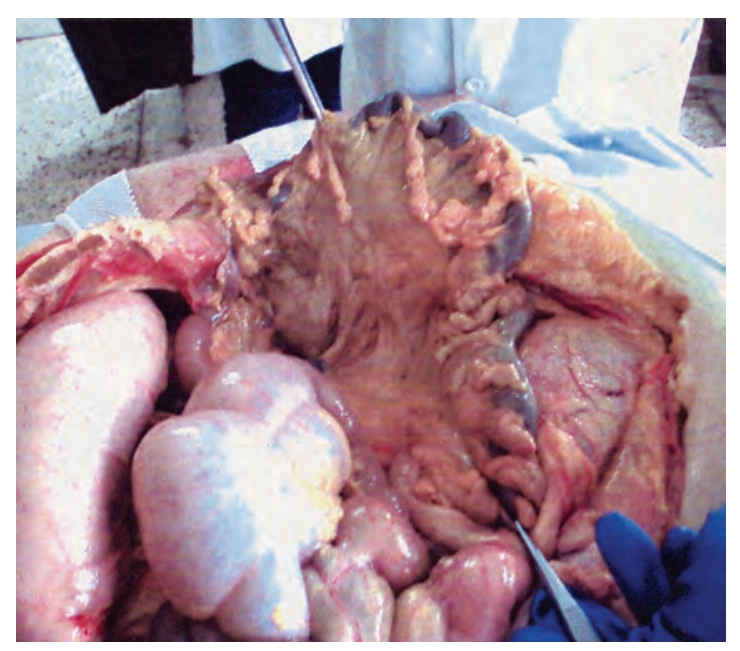

Figure 4a: Volvulus of the sigmoid colon in a fifty two year old male

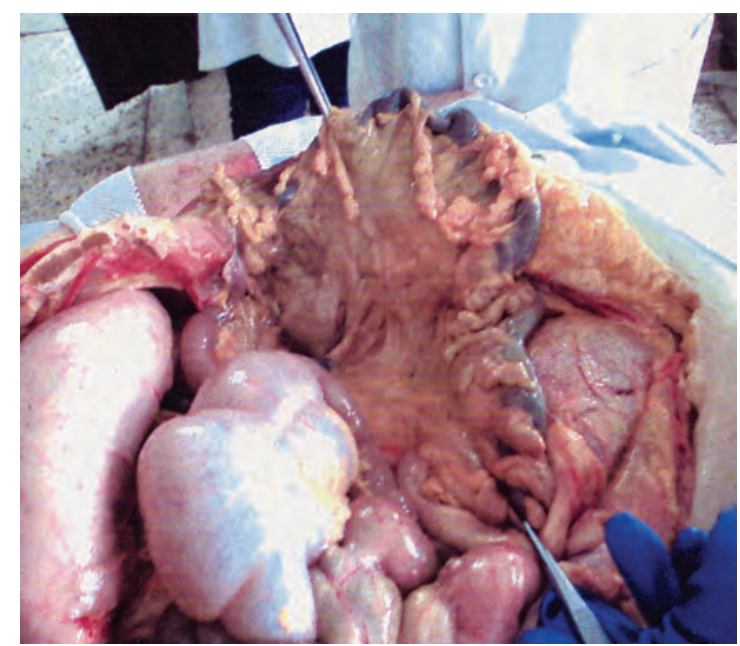

\section{Discussion}

Observations of the present study indicate significantly longer sigmoid loops for males than females. These findings support and extend those of previous reports in other populations. Ertem (1995) reported a mean sigmoid colon length of $38.9 \mathrm{~cm}$ for adult males and $34.2 \mathrm{~cm}$ for adult females in Turkey (3). Bhatnagar et al (1) described a gender difference in mean length of the human sigmoid colon in adult Indians. The study by Bhatnagar et al used fifty one live subjects and reported a much longer loop for the population $(46.5 \mathrm{~cm}$ males, $36.8 \mathrm{~cm}$ females) than we have reported in this study. Presumably, the discrepancy was occasioned by post-fixation shrinkage of the sigmoid in our subjects. Unsurprisingly, in their subgroup of 
16 fixed cadavers in the same article, Bhatnagar et al report average loop lengths of $26.5 \mathrm{~cm}$ for males and $36.5 \mathrm{~cm}$ for females.

Population studies have shown that sigmoid volvulus is more common in males than in females $(1,3)$ implicating a morphometric basis in the susceptibility to this pathology. The longer sigmoid loop in males may be the anatomic factor. Morphometric dimensions of the sigmoid mesocolon studied here also showed significant gender difference. The root length was $14.3 \mathrm{~cm}$ for males and $18.4 \mathrm{~cm}$ for females (average, $16.0 \mathrm{~cm})(\mathrm{P}=0.012)$. Previous studies suggest that individuals with a long sigmoid colon length and short mesocolon root length are more susceptible to volvulus (1). From indices calculated in this study, taking account of these colon and mesocolon dimensions, index 1 was 2.68 for males and 1.76 for females while index 2 was 1.22 for males and 0.74 for females.

Both indices indicated that males in the studied population are more prone to volvulus formation than females. The current results therefore extend the observation that the sigmoid mesocolon in the male is dolichomesocolic (longer than wide), whereas the female mesocolon is brachymesocolic (wider than long) (1). Accordingly, the narrower mesocolic root and a longer vertical length of the mesocolon make the male sigmoid colon more prone to volvulus (3).

In conclusion the adult male sigmoid colon is longer in males than in females with a shorter root length. This pattern, added to a longer mesocolic height forms the anatomical basis for higher prevalence of sigmoid volvulus in males in Africa.

\section{References}

1. Bhatnagar B.N., Sharma L.C. and Gupta S.N. Study of the anatomic dimensions of the human sigmoid colon. Clin.Anat. 2004; 17: 236-243.

2. Kohn G.J., Rosnequist C.J. and Lawson M.J. Diverticular disease and sigmoid colon length in southeast Asians and Caucasians. Med. Sci. Res. 1992; 20: 407-408.

3. Ertem M., Tanyleli E. and Erguny S. Measurement of the sigmoid colon and its relationship to volvulus. Bull. Assoc. Anat. 1995; 79: 5-6.

4. Gama A.H., Haddad J., Simonsen O., et al. Volvulus of the sigmoid colon in Brazil. Dis. Colon Rectum. 1976; 19: 314-320.

5. Madiba T.E. and Thomson S.R. The management of sigmoid volvulus. J.R. Coll. Surg. Edinb. 2000; 45: 74-80.

6. Mokoena T.R. and Madiba T.E. Sigmoid volvulus among Africans in Durban. Trop. Geog. Med. 1995; 47: 216-217.

7. Ali M.K. Treatment of sigmoid volvulus: Experience in North-West Ethiopia. Ethiop. Med. J. 1998; 36: 47-50.

8. Watters D.A., Smith A.N. and Eastwood M.A. Mechanical properties of the colon: Comparison of the features of the African and European colon in Vitro. Gut. 1985; 26: 384-392. 